\title{
Emprego de diferentes protocolos de inseminação artificial (IA) em suínos das raças Landrace e Large White
}

\author{
Use of different protocols of artificial insemination (AI) in Landrace and \\ Large White swine breed
}

\author{
Alisson Bruno de Moraes Giacomeli ${ }^{[a]}$, Luiz Ernandes Kozicki ${ }^{[b]}$, Naréu Simas de Carvalho ${ }^{[c]}$
}

[a] Médico veterinário, Pontifícia Universidade Católica do Paraná (PUCPR), Curitiba, PR - Brasil, e-mail: alissongiacomeli@hotmail.com

${ }^{[b]}$ Médico veterinário, professor Doutor da Pontifícia Universidade Católica do Paraná (PUCPR), Curitiba, PR - Brasil, e-mail: kozicki.1@pucpr.br

[c] Graduanda de Medicina Veterinária da Pontifícia Universidade Católica do Paraná (PUCPR), Curitiba, PR - Brasil, e-mail: nareu.carvalho@yahoo.com.br

\section{Resumo}

O objetivo da presente pesquisa foi avaliar três diferentes protocolos de inseminação artificial (IA) e um com monta natural em reprodutoras suínas, no sentido de comparar o número de leitões nascidos entre os grupos, considerando a raça e ordem de parto, assim como a taxa de prenhez. Foram utilizados 273 animais pluríparos e 232 primíparos, provenientes de uma granja comercial de suínos de elevado valor genético. A definição do critério utilizado para o emprego dos protocolos nas porcas foi o intervalo desmame-estro (IDE). As porcas com IDE de até 4 dias foram submetidas ao protocolo 1 (G1) (IAs às 12-36 e 48 horas), e os animais com IDE de 5 a 7 dias, ao protocolo 2 (G2) (IAs às 12-24-36 horas). Âs marrãs (primíparas) que eram destinadas a serem avós aplicou-se o protocolo 3 (G3) (IAs às 0-12-24 horas), e as que eram destinadas a serem bisavós receberam o protocolo 4 (G4) (cobertura natural no momento da observação do estro e a segunda 24 horas após). Ao se comparar os dados dos protocolos empregados, verificou-se que o protocolo 1 (G1) foi o mais utilizado pelo maior número de ocorrências, porém o mais eficiente foi o G2, com a média de leitões nascidos superior aos animais do $G 1(p>0,05)$. Nas primíparas do $G 3$ a média de leitões nascidos foi superior aos animais do G4 ( $p<0,01)$. O G4 utilizado nas primíparas com intervalos de 24 horas entre as coberturas naturais reduziu o desempenho reprodutivo. Concluiu-se que nos animais pluríparos com IDE de até 4 dias, o melhor protocolo a ser empregado foi o direcionado ao G2, e nos primíparos o ideal é manter um protocolo de IA em que o intervalo entre as IAs ou coberturas seja de 12 horas.

Palavras-chave: Suínos. Inseminação artificial. Intervalo desmame/estro. Ordem de parto. 


\begin{abstract}
The aim of this study was to evaluate three different protocols for artificial insemination (AI) and one with natural mating in breeding sows in order to compare the number of piglets born between groups, considering the race and parity, as well as the rate pregnancy. We used 273 pluriparous animals and 232 primiparous, from a commercial farm pigs of high genetic value. The definition of the criterion for the use of protocols in the nuts was weaning-estrus interval (IDE). Thus, nuts IDE up to 4 days received the protocol 1 (G1), and animals IDE 5 to 7 days received the protocol 2 (G2). For gilts, animals that were destined to be grandparents received the protocol 3 (G3), and the ones destined to be great-grandparents received the protocol 4 (G4). Comparing the data from protocols used in the nuts was found that the protocol 1 (G1) was more frequent, but more efficient protocol was 2 (G2), with an average of piglets born superior to the animals of G1 $(p>0,05)$. For gilts might be evidence that animals in $G 3$ had an average of piglets born to the animals than the G4, and protocols used in gilts with 24-hour intervals between insemination doses reduce the reproductive performance of primiparous. In sows, one can conclude is necessary to change the protocol used in animals IDE up to 4 days, and gilts, the ideal is always to keep a protocol of IA where the interval between inseminations of 12 hours, thereby aiming to make the most the potential of breeding and thus achieve greater profitability in the property.
\end{abstract}

Keywords: Pigs. Artificial Insemination. Weaning-estrus interval. Order of birth.

\title{
Introdução
}

A suinocultura moderna e tecnificada utiliza-se da inseminação artificial (IA) como componente do manejo reprodutivo. A grande difusão da IA deveu-se principalmente ao surgimento de linhagens genéticas de reprodutores, agregando as qualidades requeridas pela tipificação de carcaça exigida na indústria de carnes. A necessidade de se atender às demandas do mercado consumidor no que diz respeito à qualidade da carne e ao teor de gordura na carcaça foi a principal responsável pelo progresso genético nesta área (BORTOLOZZO et al., 2005b).

O sucesso de programas de IA em suínos depende do momento em que se realiza a deposição do sêmen no trato genital feminino com relação à ovulação. Segundo Wentz et al. (2000), os melhores resultados são alcançados quando a IA é realizada até 16 horas antes da ovulação, em se tratando de marrãs, ou de até 24 horas, em porcas. Existe considerável variação individual entre o início do estro e o momento da ovulação nos animais. Por isso, na prática recomenda-se o emprego de várias inseminações artificiais (IAs), visando a aproximar uma delas do momento da ovulação. A receptividade sexual média varia entre 40 e 60 horas. A duração do período do estro puberal é mais curta (em torno de 47 horas) que os posteriores (por volta de 56 horas). Os ovócitos são liberados entre 38 e 42 horas após o início do estro e a duração do processo ovulatório é de 3,8 horas (HAFEZ; HAFEZ, 2004).

O desempenho reprodutivo em suínos é medido principalmente pelo número de leitões vivos no parto e no desmame e pelo peso total de ambos, produzidos por porca por ano. A taxa de ovulação continua a aumentar nas gestações subsequentes, mas o tamanho da leitegada alcança o nível máximo por volta do quarto ou quinto parto (HAFEZ; HAFEZ, 2004). Segundo Alvarenga et al. (2005), a fêmea suína, em geral, ovula no terço final do estro, mas a duração do estro é muito variável, dificultando a definição de protocolos eficientes de IA. A ultrassonografia permite um diagnóstico preciso do momento da ovulação, mas seu uso como rotina é limitado pelo alto custo e pela necessidade de mão de obra especializada. Assim, na maioria das granjas os protocolos de IA são definidos como base no perfil estral das fêmeas, a partir da detecção de estro por meios convencionais, utilizando-se o intervalo desmame-estro (IDE) como estimativa da duração do estro.

Para Bortolozzo et al. (2005), vários fatores influenciam diretamente o IDE, associados principalmente à duração da lactação, ao manejo nutricional, ao grau de estimulação com o macho, à genética, à ordem de parto, ao tipo de alojamento, ao tamanho da leitegada no desmame e ao grau de estimulação durante a amamentação.

Rev. Acad., Ciênc. Agrár. Ambient., Curitiba, v. 8, n. 3, p. 333-339, jul./set. 2010 
As fêmeas com ordem de parto mais avançada são menos predispostas aos problemas de IDE prolongado ou anestro. A diminuição do desempenho reprodutivo de fêmeas com ordem de parto menor, pode ser explicada, em parte, por questões nutricionais. As primíparas são especialmente mais susceptíveis, por apresentarem maior demanda de nutrientes, pois ainda não atingiram seu tamanho e peso adulto, e por apresentarem reservas de proteína e gordura corporais limitadas. Associado a isso, as primíparas apresentam menor capacidade digestiva, o que interfere na quantidade de alimento ingerido durante a lactação, que é um período crítico e dependente para o desempenho reprodutivo posterior. Outro ponto importante é o fato de que as matrizes modernas apresentam leitegadas numerosas já ao primeiro parto, tendo, portanto, um grande desgaste gestacional e lactacional.

Ao definir o momento e a frequência ideal de realização da IA, parte-se do princípio de que o diagnóstico do estro é realizado corretamente, duas vezes ao dia, e que a dose inseminante empregada tem qualidade garantida (BENNEMANN, 2008). Para Wentz et al. (2001), o desempenho reprodutivo em suínos pode ser avaliado tendo como base o número de leitões produzidos por fêmea ao ano. Esse índice é influenciado diretamente pelo número de partos que cada matriz produz por ano e pelo número de leitões desmamados por leitegada. Uma série de fatores, como genótipo, sanidade, nutrição, manejo e ambiente, entre outros, pode influenciar o desempenho reprodutivo do rebanho. Silveira (2009) defende que as duas principais causas de pequenas leitegadas estão associadas à baixa taxa de ovulação ou de fecundação e à mortalidade embrionária entre 15 e 30 dias de gestação, que pode ser ocasionada por brigas e até mesmo por infecções do trato genito-urinário da fêmea.

Estudo realizado por Carvalho et al. (2003) ressaltou que o aumento na taxa de ovulação não foi seguido pelo aumento significativo da leitegada, e que a alta taxa de ovulação foi negativamente correlacionada com a sobrevivência embrionária.

Silveira et al. (2005) afirmam que o manejo pós-cobrição e os cuidados na fase inicial da gestação têm a sua importância no desempenho reprodutivo, pois após a fecundação dos óvulos serão fundamentais o desenvolvimento e a fixação dos embriões no útero. Assim, durante o primeiro mês de gestação, a sobrevivência embrionária se torna determinante para o sucesso reprodutivo. Nessa fase, a mortalidade de embriões pode ser importante. Na espécie suína ocorrem índices em torno de $40 \%$ de perdas durante a gestação, e $75 \%$ dessas perdas ocorrem na fase embrionária. Existe grande variação de uma porca para outra quanto ao montante de perdas embrionárias, mas é certo que, em algumas porcas, as falhas de manejo irão provocar retornos ou pequenas leitegadas (SILVEIRA, 2009).

O objetivo da presente pesquisa foi o de avaliar diferentes protocolos de IA e cobertura natural e comparar o número de leitões nascidos entre os grupos, considerando a raça e ordem de parto, assim como a taxa de prenhez.

\section{Materiais e métodos}

Foram utilizados dados de 273 pluríparas e 232 primíparas, provenientes de uma granja comercial de suínos de alto valor genético no interior do Estado de Santa Catarina, Brasil. Os dados coletados foram referentes ao período de cobertura, gestação e parição, do mês de janeiro até o fim de março de 2009. Os dados analisados foram provenientes de cruzamentos entre raças, Large White avó $(\mathrm{LwP}) \times$ Landrace e Landrace avó $(\mathrm{LaP}) \times$ Large White, para produção das fêmeas reprodutoras $(\mathrm{F} 1)$, e cruzamentos entre animais de mesma raça, Large White bisavó $(\mathrm{LwB}) \times$ Large White e Landrace bisavó $(\mathrm{LaB}) \times$ Landrace, com a finalidade de reposição de avós e bisavós no plantel. Além da variável raça, os animais foram separados durante o estudo, analisando-se a ordem de parto (OP), o número de leitões nascidos totais (LNT), e os diferentes tipos de protocolo de IA utilizados na granja. A definição do critério utilizado para o emprego dos protocolos nas porcas foi o intervalo desmame-estro (IDE). Na sequência realizou-se a divisão dos grupos, isto é, os animais que eram detectados em estro até o $4^{\circ}$ dia pós-desmame eram submetidos ao protocolo 1 (G1); os animais que demonstravam estro entre o $5^{\circ}$ e $7^{\circ}$ dia pós-desmame eram submetidos ao protocolo 2 (G2). Os animais que manifestavam o estro a partir do $7^{\circ}$ dia pós-desmame não entraram no experimento. O protocolo 1 de inseminações artificiais (12-36-48 horas) estabeleceu que a primeira dose de sêmen fosse aplicada 12 horas após a identificação da manifestação do estro, e a última era realizada 48 horas após a verificação do estro. 
O protocolo 2: 12-24-36 horas, executando-se a primeira dose de sêmen às 12 horas após o estro e a última, 36 horas. Nas marrãs (nulíparas destinadas a serem avós) aplicou-se o protocolo 3 (G3): isto é, IA a 0-12-24 horas, em que a primeira dose de sêmen era depositada no útero do animal no ato da identificação do estro e a última, 24 horas após a visualização do cio. Em outro grupo (G4) de marrãs (destinadas a serem bisavós) aplicou-se o protocolo de duas coberturas naturais (mesmo reprodutor), sendo a primeira no momento da verificação do estro e a segunda, 24 horas depois. Para a análise estatística dos dados dentro dos grupos foi utilizada a análise de variância (ANOVA one-way). Para verificar as diferenças, aplicou-se o teste de comparações múltiplas de Bonferroni e para as análises entre os grupos foi utilizado o teste Mann-Whitney. O nível de significância adotado foi $5 \%(\alpha=0,05)$. Todos os cálculos foram realizados utilizando o software estatístico GraphPad Prism version 3.00 for Windows ${ }^{\circledR}$ (San Diego, Califórnia, EUA).

\section{Resultados e discussão}

Ao se comparar os dados dos protocolos empregados nas porcas (Tabela 1), verificou-se que o G1 foi o mais utilizado, visto que a maioria dos animais apresentou IDE de até quatro dias. A taxa de parição dos animais deste protocolo foi de $86,5 \%$ e a média de LNT foi de 11,3 leitões por parto. Os animais submetidos ao protocolo 2 (G2) demonstraram taxa de parição de 85,8\% e a média de LNT foi de 11,4 leitões por parto. Por sua vez, as marrãs demonstraram taxa de parição no protocolo 3 (G3) de 76,6\%, com média de LNT de 11,5 leitões $(\mathrm{p}<0,05)$ por parto. As marrãs submetidas ao G4 apresentaram taxa de parição de 83,3\%, com média de 10,3 leitões nascidos totais por parto. Relativamente às diferenças do número de leitões e aos protocolos empregados nas porcas, observa-se que no G2 a média de LNT foi superior ao G1, acusando diferença de 0,12 leitões por parto $(p>0,05)$. Muito embora essa diferença não tenha sido significativa, pode-se inferir que 0,12 leitões por parto causará impacto sobre a lucratividade do produtor, principalmente ao se trabalhar com grande número de matrizes, gerando consequentemente um número maior de leitões. Os animais do G1 inseminados classificam-se como os mais prolíferos do plantel, visto que apresentaram o IDE mais curto. Com o IDE mais curto, espera-se do animal um período estral mais prolongado, concordando com estudos realizados por Viana et al. (1999) e Alvarenga (2005), ao confirmarem a existência de relação inversa entre IDE e a duração do cio (DC) - ou seja, quanto maior o IDE, menor é a DC. Isso acaba viabilizando e aumentando as chances de maior número de espermatozoides fecundarem maior número de oócitos nos animais com IDE curto, produzindo assim um número maior de leitões, quando comparado com animais de IDE longo. Como o esperado não ocorreu, é importante considerar que a diferença pode estar associada ao tipo de protocolo utilizado (Tabela 1 e 2).

A ordem de parto é um fator muito importante, pois na medida em que a OP aumenta, o número de LNT tende a aumentar. Segundo Amaral et al. (2005), há um aumento linear do tamanho da leitegada do primeiro ao sétimo parto, embora alguns rebanhos apresentem queda do número de leitões nascidos no segundo parto, quando o de leitões no primeiro parto for elevado. Ao contrário, fêmeas que apresentam leitegadas menores $(<10)$ no primeiro parto tendem a apresentar aumento linear nos partos subsequentes.

Os dados de análise considerando a raça, ordem de parto e o tipo de protocolo utilizado nas porcas podem ser observados nas Tabelas 1 e 2 .

Analisando-se os dados das Tabelas 1 e 2, relativas às raças e à ordem de parto verifica-se uma tendência de aumento do número de leitões à medida que a OP aumenta, corroborando afirmações de Viana et al. (1999) e Alvarenga (2005). Especificamente à raça, pode-se observar que a administração do protocolo 2 para as porcas Landrace bisavós (LAB) e Landrace avós (LAP) foram mais eficientes que o protocolo 1 ( $p>0,05)$. Relativamente aos animais da raça Large White bisavós (LwB) e Large White avós (LwP), o protocolo 1 demonstrou ser mais eficaz, porém não houve diferença estatística. Em função disso, é possível que a DC (duração do cio) da raça

Large White seja menor que a da Landrace. Assim, o protocolo 2, com duração de 36 horas de aplicação de sêmen, avantajou-se sobre o protocolo 1 (48 horas de aplicação do sêmen), para esta raça. Porém, como os animais que foram inseminados aplicando-se o protocolo 1 são considerados como os mais prolíferos, pode ter ocorrido que o protocolo 1 não tenha obtido um desempenho satisfatório. Sendo a DC mais longa nestes animais com IDE mais curto, o ideal seria aplicar a primeira dose de sêmen mais tarde, isto é, ao invés de fazer 
12 horas após a detecção do cio, realizar 24 horas após a identificação deste, conforme relatos de Alvarenga et al. (2005), ao afirmarem que nestes animais a ovulação ocorre no terço final do estro. Na sequência, duas aplicações consecutivas de sêmen, de 12 horas de intervalo entre elas, poderiam ser adotadas, estabelecendo assim outro protocolo (24-36-48). Silveira et al. (2005) e Bennemann et al. (2008) demonstraram que a eficiência de protocolos de IA com apenas duas aplicações são igualmente eficazes ao se comparar com protocolos de três inseminações. Sugere-se a possibilidade da utilização de protocolo baseado em apenas duas inseminações, ou seja, às 24 horas e às 36 horas após a identificação do estro nos animais com IDE de até 4 dias, reduzindo-se com essas medidas o número de doses de sêmen utilizadas além da redução de manejo.

Tabela 1 - Dados obtidos da aplicação de G1 e G2 em porcas da raça Landrace, leitões nascidos totais (LNT) e ordem de parto $(\mathrm{OP}) 2,3$ e $>4$ partos. $(\mathrm{n}=143)$

\begin{tabular}{|c|c|c|c|c|c|c|}
\hline \multirow{2}{*}{ Protocolos } & \multicolumn{3}{|c|}{ N. de animais $L A B$ segundo a $O P$} & \multicolumn{3}{|c|}{ LNT segundo a OP } \\
\hline & 2 & 3 & $>4$ & 2 & 3 & $>4$ \\
\hline G1 (IDE até 4 dias) & 9 & 12 & 20 & $11,3 \pm 2,73$ & $10,67 \pm 4,18$ & $11,50 \pm 2,18$ \\
\hline G2 (IDE de 5 a 7 dias) & 4 & 4 & 9 & $11,75 \pm 2,06$ & $14,25 \pm 4,19$ & $12,56 \pm 4,27$ \\
\hline \multirow{2}{*}{ Protocolos } & \multicolumn{3}{|c|}{ N. de animais LAP segundo a OP } & \multicolumn{3}{|c|}{ LNT segundo a OP } \\
\hline & 2 & 3 & $>4$ & 2 & 3 & $>4$ \\
\hline G1 (IDE até 4 dias) & 3 & 16 & 49 & $15,00 \pm 2,00$ & $12,00 \pm 3,55$ & $11,79 \pm 3,04$ \\
\hline G2 (IDE de 5 a 7 dias) & 9 & 2 & 6 & $13,00 \pm 3,12$ & $11,00 \pm 2,82$ & $12,80 \pm 3,27$ \\
\hline
\end{tabular}

Nota: G1 (IAs às 12-36-48 horas pós a verificação do estro); G2 (IAs às 12-24-36 horas pós a verificação do estro); LAB (Landrace bisavó); LAP (Landrace avó)

Tabela 2 - Dados obtidos da aplicação dos protocolos G1 e G2 em porcas da raça Large White, leitões nascidos totais (LNT) e ordem de parto (OP) 2, 3 e $>4$ partos. $(n=130)$

\begin{tabular}{|c|c|c|c|c|c|c|}
\hline \multirow{2}{*}{ Protocolos } & \multicolumn{3}{|c|}{ N. de animais LWB segundo a $O P$} & \multicolumn{3}{|c|}{ LNT segundo a OP } \\
\hline & 2 & 3 & $>4$ & 2 & 3 & $>4$ \\
\hline G1 (IDE de até 4 dias) & 6 & 15 & 11 & $9,16 \pm 3,71$ & $9,60 \pm 3,83$ & $10,73 \pm 2,97$ \\
\hline G2 (IDE de 5 a 7 dias) & 9 & 3 & 3 & $9,88 \pm 4,51$ & $10,00 \pm 1,00$ & $9,66 \pm 4,61$ \\
\hline \multirow{2}{*}{ Protocolos } & \multicolumn{3}{|c|}{ N. de animais LWP segundo a OP } & \multicolumn{3}{|c|}{ LNT segundo a OP } \\
\hline & 2 & 3 & $>4$ & 2 & 3 & $>4$ \\
\hline G1 (IDE de até 4 dias) & 8 & 17 & 34 & $10,63 \pm 2,72$ & $10,88 \pm 2,14$ & $11,94 \pm 3,36$ \\
\hline G2 (IDE de 5 a 7 dias) & 8 & 5 & 11 & $10,25 \pm 4,06$ & $10,20 \pm 3,76$ & $11,27 \pm 2,86$ \\
\hline
\end{tabular}

Nota: G1 (IAs às 12-36-48 horas pós a verificação do estro); G2 (IAs às 12-24-36 horas pós a verificação do estro); Large White Bisavó (LWB); Large White Avó (LWP)

Rev. Acad., Ciênc. Agrár. Ambient., Curitiba, v. 8, n. 3, p. 333-339, jul./set. 2010 
Observando-se a Tabela 3, verifica-se que os animais da categoria LAP obtiveram leitegada superior às demais, diferença significativa $(\mathrm{p}<0,01)$ ao se comparar com LWB. Em marrãs, os estudos do momento ótimo para a realização da IA têm apresentado resultados conflitantes. Waberski et al. (1994) observaram que o intervalo ótimo entre IA e ovulação foi de 12 horas. Em outro estudo, Uemoto et al. (1999) observaram que, quando a IA era realizada em um intervalo de até 24 horas antes da ovulação, a taxa de prenhez e número de embriões não eram afetados ( $p>0,05)$. Em outro experimento realizado por Bennemann et al. (2005) foram inseminadas 218 leitoas em diferentes intervalos pré-ovulatórios. Não foram observadas diferenças na taxa de prenhez e número de embriões quando as inseminações foram realizadas até 30 horas antes da ovulação ( $p>0,05)$. Segundo Bortolozzo et al. (2005a), quando uma população espermática é depositada no trato genital de uma marrã em período superior a 16 horas antes da ovulação, há aparentemente uma queda no desempenho reprodutivo. Bennemann et al. (2008) conduziram um experimento, dividindo-se os animais em dois tratamentos, sendo que um grupo de animais foi inseminado duas vezes ao dia, em intervalos de 12 horas ou uma vez ao dia, em intervalos de 24 horas. As leitoas submetidas às IAs com 24 horas de intervalo não apresentaram diferença na taxa de retorno ao estro e taxa de parto ajustada ( $p>0,05)$; no entanto, tiveram uma redução na taxa de parto e tamanho da leitegada. Nossos resultados se aproximam dos relatados pelos autores supracitados, relativamente às fêmeas inseminadas a intervalos de 12 horas, ao parirem maior número de leitões por parto do que as fêmeas cobertas com intervalo de 24 horas pela monta natural. Nesse caso, sugere-se o emprego do protocolo 3 tanto para avós quanto para bisavós.

Tabela 3 - Dados obtidos da aplicação dos protocolos G3 e G4 em marrãs da raça Landrace e Large White, de acordo com a categoria, numero de animais prenhes e percentagem e média da leitegada

\begin{tabular}{lcccc}
\hline Grupos & Categoria & N. de animais & $\mathbf{( \% )}$ & Média de leitões/leitegada \\
\hline \multirow{2}{*}{ G3 } & LAP & $52 / 62$ & 83,9 & $12,3 \pm 3,7^{\mathrm{a}}$ \\
& LWP & $43 / 62$ & 69,3 & $10.5 \pm 3,7^{7^{\mathrm{b}}}$ \\
\hline \multirow{2}{*}{ G4 } & LAB & $26 / 54$ & 41,1 & $10,8 \pm 3,3^{\mathrm{ab}}$ \\
& LWB & $54 / 64$ & 84,3 & $9,9 \pm 3,4^{\mathrm{b}}$ \\
\hline
\end{tabular}

Nota: G3 (IAs às 0-12-24 horas após a verificação do estro); G4 (coberturas de 0 e às 24 horas após verificação do estro); Letras diferentes na mesma coluna indicam significância. ( $\mathrm{p}<0,01)$; LAP - Landrace avó; LWP - Large White avó; LAB - Landrace bisavó; LWB - Large White bisavó

\section{Conclusão}

Nas porcas, pode-se concluir que houve melhor eficiência do protocolo 2 em relação ao 1 (muito embora não tenha havido diferença estatística), isto é, as IAs devem seguir o padrão de 12-24-36 horas após a verificação do estro, para os animais com IDE de até 4 dias. Para as marrãs, o ideal é manter um protocolo de IA ou de monta natural, em que o intervalo da introdução do sêmen no trato uterino seja de 12 em 12 horas.

\section{Referências}

ALVARENGA, M. V. F. et al. Sensibilidade e especificidade do perfil estral no diagnóstico da ovulação em fêmeas suínas. In: CONGRESSO DA ABRAVES, 12., 2005, Fortaleza. Anais... Pelotas: Universidade Federal de Pelotas, Rio Grande do Sul, 2005.

Rev. Acad., Ciênc. Agrár. Ambient., Curitiba, v. 8, n. 3, p. 333-339, jul./set. 2010 
AMARAL, W. S. et al. Desempenho reprodutivo até o terceiro parto de acordo com o tamanho da primeira leitegada de fêmeas suínas. In: CONGRESSO DA ABRAVES, 12., 2005, Fortaleza. Anais... Pelotas: Universidade Federal de Pelotas, Rio Grande do Sul, 2005.

BENNEMANN P. E. et al. Artificial insemination of gilts with 1,5 billion sperms stored in different periods associated with different pre-ovulatory intervals. Reproduction in Domestic Animal, v. 40, p. 507-510, 2005.

BENNEMANN, P. E. Protocolos emergenciais para programas de inseminação artificial em suínos. Acta Scientiae Veterinariae, v. 36, p. 27-32, 2008.

BORTOLOZZO, F. P. et al. Influence of time of insemination relative to ovulation and frequency of insemination on gilt fertility. Theriogenology, v. 64, p. 1956-1662, 2005a.

BORTOLOZZO, F. P. et al. Situação atual da inseminação artificial em suínos. Acta Scientiae Veterinariae, v. 33, n. 1, p. 17-32, 2005b.

CARVALHO, L. F. R. et al. Efeito da aplicação de hCG ou GnRH sobre a concentração sérica de progesterona e eficiência reprodutiva em porcas. Arquivo Brasileiro de Medicina Veterinária e Zootecnia, v. 55, n. 6, p. 659-664, 2003.

HAFEZ, E. S. E.; HAFEZ B. Reprodução animal. 7. ed. São Paulo: Manole, 2004.

OLLHOFF, R. D. Uso da resina acrílica em descornas. Fazenda Rio Grande: PUCPR, 2009. Comunicação oral.

SILVEIRA, P. Manejo da porca: pós-inseminação até a confirmação da prenhez. Suinocultura Industrial, n. 6, p. 35-54, 2009.

SILVEIRA, P. R. S. et al. Eficiência de protocolo de inseminação artificial de porcas com duas versus três doses durante o mesmo estro. In: CONGRESSO DA ABRAVES, 12., 2005, Fortaleza. Anais... Pelotas: Universidade Federal de Pelotas, Rio Grande do Sul, 2005.

UEMOTO, D. A. Comportamento estral e desempenho reprodutivo de leitoas submetidas à inseminação artificial em diferentes períodos pré-ovulatórios. 1999. 96 f. Porto Alegre, RS. Dissertação (Mestrado em Ciências Veterinárias) - Programa de Pós-Graduação em Ciências Veterinárias, Universidade Federal do Rio Grande do Sul, Porto Alegre, 1999.

VIANA, C. H. C. et al. Relações entre as características intervalo desmame-cio, duração do cio e momento da ovulação diagnosticado pela ultra-sonografia em fêmeas da espécie suína. Brazilian Journal of Veterinary Research and Animal Science, v. 36, 1999.

WABERSKI, D. et al. Effect of time of insemination relative to ovulation on fertility with liquid and frozen boar semen. Theriogenology, v. 42, p. 831-840, 1994.

WENTZ, I. et al. Desempenho reprodutivo de marrãs submetidas à infusão transcervical de plasma seminal no estro da cobertura. Ciência Rural, v. 30, n. 6, p. 1027-1031, 2000.

WENTZ, I. et al. A hipertermia durante o estro pode afetar o desempenho reprodutivo de fêmeas suínas. Ciência Rural, v. 31, n. 4, p. 651-656, 2001.

Recebido: 12/12/2009

Received: 12/12/2009

Aprovado: 12/05/2010

Approved: 05/12/2010

Rev. Acad., Ciênc. Agrár. Ambient., Curitiba, v. 8, n. 3, p. 333-339, jul./set. 2010 